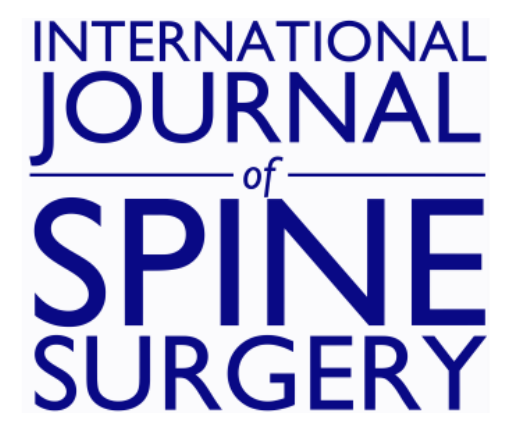

\title{
A Review of Symptomatic Lumbosacral Transitional Vertebrae: Bertolotti's Syndrome
}

Jeffrey M. Jancuska, Jeffrey M. Spivak and John A. Bendo

Int J Spine Surg 2015, 9 ()

doi: https://doi.org/10.14444/2042

http://ijssurgery.com/content/9/42

This information is current as of April 26, 2023.

Email Alerts Receive free email-alerts when new articles cite this article. Sign up at:

http://ijssurgery.com/alerts

The International Journal of Shing Surgerih 2397 Waterbury Circle, Suite 1,

Aurora, IL 60504, Phone: +1-630-375-1432

(C) 2015 ISASS. All Rights Reserved. 


\section{A Review of Symptomatic Lumbosacral Transitional Vertebrae: Bertolotti's Syndrome}

Jeffrey M. Jancuska, BA, ${ }^{1}$ Jeffrey M. Spivak, MD, ${ }^{2}$ John A. Bendo, $M D^{2}$

${ }^{1}$ New York University School of Medicine, New York, NY, USA ${ }^{2}$ Department of Orthopaedic Surgery and Hospital for Joint Diseases, New York University School of Medicine, New York, NY, USA

\section{Abstract}

\section{Background}

Lumbosacral transitional vertebrae (LSTV) are increasingly recognized as a common anatomical variant associated with altered patterns of degenerative spine changes. This review will focus on the clinical significance of LSTV, disruptions in normal spine biomechanics, imaging techniques, diagnosis, and treatment.

\section{Methods}

A Pubmed search using the specific key words "LSTV," "lumbosacral transitional vertebrae," and "Bertolotti's Syndrome" was performed. The resulting group of manuscripts from our search was evaluated.

\section{Results}

LSTV are associated with alterations in biomechanics and anatomy of spinal and paraspinal structures, which have important implications on surgical approaches and techniques. LSTV are often inaccurately detected and classified on standard AP radiographs and MRI. The use of whole-spine images as well as geometric relationships between the sacrum and lumbar vertebra increase accuracy. Uncertainty regarding the cause, clinical significance, and treatment of LSTV persists. Some authors suggest an association between LSTV types II and IV and low back pain. Pseudoarticulation between the transverse process and the sacrum creates a "false joint" susceptible to arthritic changes and osteophyte formation potentially leading to nerve root entrapment.

The diagnosis of symptomatic LSTV is considered with appropriate patient history, imaging studies, and diagnostic injections. A positive radionuclide study along with a positive effect from a local injection helps distinguish the transitional vertebra as a significant pain source. Surgical resection is reserved for a subgroup of LSTV patients who fail conservative treatment and whose pain is definitively attributed to the anomalous pseudoarticulation.

\section{Conclusions}

Due to the common finding of low back pain and the wide prevalence of LSTV in the general population, it is essential to differentiate between symptoms originating from an anomalous psuedoarticulation from other potential sources of low back pain. Further studies with larger sample sizes and longer follow-up time would better demonstrate the effectiveness of surgical resection and help guide treatment.

KEYWORDS: LSTV, BERTOLOTTI'S SYNDROME, TRANSITIONAL VERTEBRAE

VOLUME 9 ARTICLE 42 DOI: 10.14444/2042

\section{Introduction}

Lumbosacral transitional vertebrae (LSTV) are congenital spinal anomalies, in which an elongated transverse process of the last lumbar vertebra fuses with varying degree to the "first" sacral segment. ${ }^{1}$ LSTV, as a morphological variation, spans a spectrum from partial/complete L5 sacralization to partial/complete S1 lumbarization. ${ }^{2,3}$ When the L5 vertebra fuses completely to the sacrum, 4 lumbar vertebrae exist, Downloaded from http://ijssurgery.com/ by guest on April 26, 2023 whereas when $\mathrm{S} 1$ separates entirely from the sacrum, 6 lumbar vertebrae exist and the sagittal contour of the spine becomes more lordotic. ${ }^{4}$ Many intermediate incomplete transitions have also been recognized and classified as LSTV. ${ }^{5}$

Castellvi et al. classified LSTV into 4 types (Figure 1). Type I includes unilateral (Ia) or bilateral (Ib) dysplastic transverse processes, measuring at least 19 $\mathrm{mm}$ in width (craniocaudad dimension). Type II ex- 
hibits incomplete unilateral (IIa) or bilateral (IIb) lumbarization/sacralization with an enlarged transverse process that has a diarthrodial joint between itself and the sacrum. Type III LSTV describes unilateral (IIIa) or bilateral (IIIb) lumbarization/sacralization with complete osseous fusion of the transverse process(es) to the sacrum. Type IV involves a unilateral type II transition with a type III on the contralateral side. ${ }^{3,6}$

Estimates of the prevalence of LSTV in the general population vary widely throughout the literature due to differences in definition and diagnostic modalities, ranging from $4.0 \%-35.9 \%$ with a mean of $12.3 \% .^{3,5,7,8} \mathrm{In}$ a study of 211 participants, Apazidis et al. determined Type IA most common with a prevalence of $14.7 \% ;^{7}$ however, Type I is generally considered to have no clinical significance and does not require further attention in clinical practice. ${ }^{6}$ In an asympto-

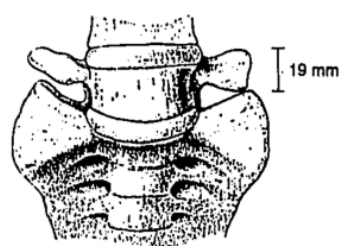

IA
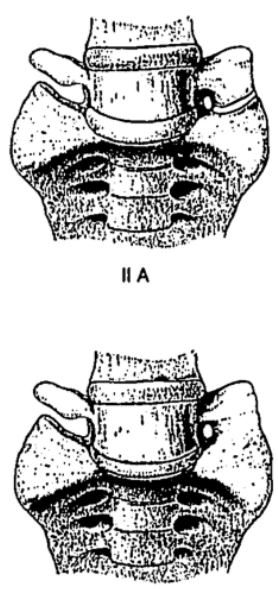

III A

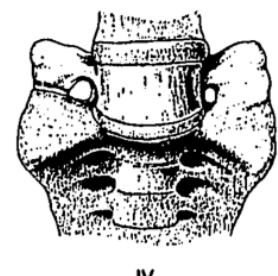

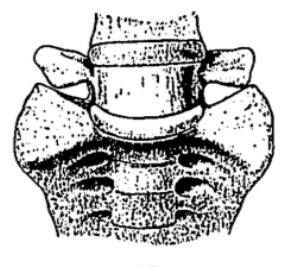

18
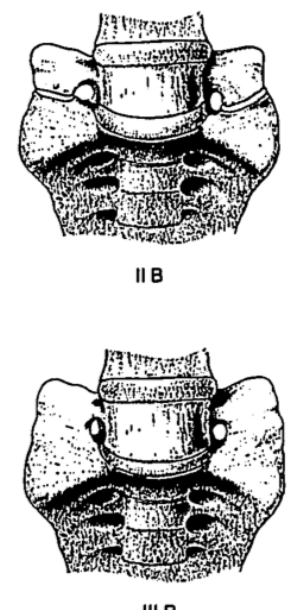

III B
Fig. 1. Castellvi radiographic classification system. ${ }^{6}$ matic population, Nardo et al. determined that Type I and Type II were each responsible for more than $40 \%$ of total occurrences of LSTV, while Type III and Type IV accounted for $11.5 \%$ and $5.25 \%$ of occurrences, respectively. ${ }^{9}$ In unilaterally occurring malformations, the incidence is significantly higher on the left side, a finding which remains unexplained. ${ }^{10}$

The prevalence of LSTV is higher in men compared to women $(28.1 \%$ vs. $11.1 \%) .{ }^{9}$ Sacralization is more common in males, meanwhile accessory L5-S1 articulations and lumbarization of $\mathrm{S} 1$ are more common in women. ${ }^{11}$ Cases of families with increased incidence of LSTV suggest a genetic component. ${ }^{12}$ HOX10/HOX11 genes influence axial pattern of lumbar and sacral vertebrae. Mutations in these genes may play a role in the formation of LSTV. ${ }^{5}$

\section{Anatomical Variations}

The presence of an LSTV disrupts normal spine biomechanics and anatomy. The sacrum, lying at the base of the vertebral column, optimizes the dissipation of the weight of the upper body toward the sacroiliac (SI) joint by working as a fused mass of boney elements. ${ }^{11}$ The sacrum's ability to dissipate load depends on its size and its surface area with the SI joint. Although HOX genes regulate segmentation of the vertebral column into individual vertebral segments, formation of transitional states at the lumbosacral junction may be greatly influenced by the functional requirements of load transmission at the SI junction. According to cadaver studies, sacra incorporating L5 possess significantly smaller heights than the normal sacra if the fused L5 vertebra is excluded from the measurement. This process of "addition" or "diminution" of segments to or from the sacrum depends on the load-bearing capacity of the normal (S1-S5) sacrum at a very rudimentary stage of its formation. Therefore, a small sacrum with inadequate SI joint surface area may incorporate L5 to enhance load-bearing capacity, while a sacrum with over competent load bearing capacity may release $\mathrm{S} 1 .^{13}$

Boney abnormalities associated with LSTV impact surgery in the lumbosacral region. In the case of sacralization, all dimensions, including pedicle

Downloaded from http://ijssurgery.com/ by guest on April 26, 2023 
height, sagittal and transverse dimensions, and sagittal angulation are reduced, and downward slope is increased. ${ }^{14}$ The height of the pars interarticularis (PI) and the widths of laminae are significantly smaller in the terminal lumbar segment of sacralized specimens. Small PI may predispose spondylolysis and spondylolisthesis at lumbo-sacral junctions associated with transitional variations, and warrant special attention to avoid iatrogenic injuries. ${ }^{15}$ Lumbarization of $\mathrm{S} 1$ results in a shorter distance between facet and sacral promontory, more obtuse pedicles in the sagittal plane and less steep in front. Therefore, pedicle screws should be directed more obtusely in the sagittal plane and at a reduced downward inclination. ${ }^{14}$ LSTV possess a reduced number of trabeculae of cancellous bone. Consequently, screw placements and subsequent pullouts should be reviewed. ${ }^{16}$

LSTV exhibit altered articular facets at the L5-S1 junction such that the facets are smaller and more coronally oriented. Lumbarization results in the smallest facet linear dimension, smallest surface area, and maximal coronal orientation. Sacralization demonstrates insignificant alteration in facet morphology. Facet asymmetry is predominantly associated with accessory L5-S1 articulations, but is seen in all LSTV subtypes. These alterations are possibly related to low back pain situations. ${ }^{17}$

The association between LSTV with morphological alterations of neural arch elements and auricular surfaces is well established. Considering the biomechanical importance of these morphological alterations in maintaining stability of the lumbar spine, Mahato suggests re-defining and modifying the current classification of LSTV. Including facet and auricular surface status would allow clinicians to clearly delineate the entire range of information required to visualize and clinically interpret any subtype of LSTV affliction (Table 1). ${ }^{2}$

The disc height below a lumbosacral segment is significantly decreased in LSTV types II, III, and IV. ${ }^{18,19}$ The presence of a bilateral boney fusion decreases disc height more severely compared to segments with potential for motion (unilateral fusion). The common finding of a narrowed L5-S1 intervertebral disc associated with an LSTV should not be consid- ered disk degeneration or displacement. ${ }^{19}$ In addition, the sagittal alignment is most commonly neutral, unlike the typical lordotic L5-S1 disc.

In an anatomical study of 70 cadavers, Aihara et al. found that the iliolumbar ligaments at the level immediately above transitional vertebrae are thinner and weaker than those in cadavers without LSTV. The weak iliolumbar ligaments result in vertebral segment instability and could subsequently lead to early disc degeneration. The formation of an articulation or boney union between vertebra and sacrum through the transverse process may represent an adaptive mechanism to compensate for a weak iliolumbar ligament and to preserve stability. ${ }^{20}$

LSTV affect the terminal level of the conus medullaris (TLCM). Compared to controls, the TL$\mathrm{CM}$ is significantly higher in the presence of a sacralized L5 and significantly lower in the presence of a lumbardized S1. This finding may help clinicians identify the neurological discrepancies observed among neurologic injuries at the thoracolumbar junction. ${ }^{21}$

In 1980, McCulloch and Waddell proposed that the functional L5 nerve root always originates from the "last mobile" segment of the spine. The last mobile segment of the spine is defined as the lowest level with a fully formed disc space, bilateral facet joints and two free transverse processes which do not articulate with the ala of the sacrum or the pelvis.Therefore, in the case of a sacralized L5, the functional L5 nerve root corresponds to the anatomical L4 nerve root. In patients with a lumbardized S1, the last fully mobile level is usually L6-S2, and the functional L5 nerve root corresponds with the L6 nerve root. ${ }^{22}$ Chang et al. agreed, concluding that neurologic symptoms caused by the L6 nerve root compression resemble those of the L5 rather than the S1 nerve root compression in the normal configuration. ${ }^{23}$ In 2008, Kim et al. suggested in the case of lumbardized S1 (L6), the distribution of motor and sensory symptoms caused by the lumbardized $\mathrm{S} 1$ (L6) nerve root stimulation is similar to that of the $\mathrm{S} 1$ nerve root stimulation in the normal configuration. ${ }^{24}$ Furthermore, Hinterdorfer et al. implemented intraoperative electrophysiological monitoring by means 
of evoked EMG to compare segmental innervation in patients with 5LVB and 6LVB. This study provides strong evidence that the function of the lumbosacral nerve root is not significantly altered in patients with $6 \mathrm{LVB}$, meaning that the $\mathrm{L} 6$ nerve root is equivalent to the $S 1$ nerve root in patients with 5LVB. In addition, the root emerging from L6/S not only primarily resembles the $S 1$ root but also shows characteristics of the $S 2$ nerve, with a tendency to innervate the biceps femoris muscle. ${ }^{25}$ Seyfert, with careful use of cremasteric reflex, concluded that lumbarization shows a dermatome gap between the lumbar dermatomes C1-C3 and the sacral dermatomes $\mathrm{S} 2$ and $\mathrm{S} 3$, which lay significantly more ventral than in patients with a normal spinal configuration. ${ }^{26}$ The alteration in nerve root innervation caused by a transitional vertebra may make it difficult to find the pain generator. Therefore, in patients receiving epidurals or selective nerve root blocks, one should be aware of a transitional segment before initiating the injection. $^{24}$

Lumbardized sacrums represent a relative con- traindication for lateral transpsoas interbody fusion at L5-6 due to migration of neural anatomy within the psoas muscle. Smith et al. reported that 8 out of 10 patients with 6 lumbar vertebrae were converted to an alternative approach after a corridor through the psoas muscle was not found. Axial MRI reveals a teardrop-shaped psoas detached from the lateral border of the disc space in patients with transitional anatomy unapproachable at L5-6, resembling L5-S1 in normal anatomy. Preoperative axial MRI and intraoperative advanced neuromonitoring can help avoid injury. ${ }^{27}$

Surgeons must consider the likelihood of vascular variation in the presence of an LSTV. According to Weiner et al., 11 out of 12 patients undergoing anterior lumbar interbody fusion at the functional junction above a fixed transitional level required significant alteration of the approach secondary to vascular variation. The more caudal location of the junction between the common iliac veins and the inferior vena cava prohibits safe access to the functional L5-S1 disc below this junction. Accordingly, an approach lateral

Table 1. Redefining lumbosacral transitional vertebrae (LSTV) classification through integrating the full spectrum of morphological alterations in a biomechanical continuum. $^{2}$

\begin{tabular}{|c|c|c|c|c|c|c|}
\hline \multirow{2}{*}{$\begin{array}{l}\text { Dysplastic L5 } \\
\text { Transverse } \\
\text { Process (TP)* }\end{array}$} & Type I A & Type I B & \multicolumn{2}{|c|}{$\begin{array}{l}\text { Type I A F (i/c) or Type I B F(i/ } \\
\text { c) }\end{array}$} & Type I A F2 or Type I B F2 & - \\
\hline & $\begin{array}{l}\text { Unilateral } \mathrm{TP} \leq 19 \mathrm{~mm} \text { in } \\
\text { width* }^{*}\end{array}$ & $\begin{array}{l}\text { Bilateral TPs } \leq 19 \mathrm{~mm} \text { in } \\
\text { width* }\end{array}$ & \multicolumn{2}{|c|}{$\begin{array}{l}\text { With presence of ipsi/contra } \\
\text { lateral rudimentary facet to the } \\
\text { side of the L5 enlargement }\end{array}$} & $\begin{array}{l}\text { With presence of bilateral } \\
\text { rudimentary facets }\end{array}$ & \\
\hline \multirow{2}{*}{$\begin{array}{l}\text { Accessory } \\
\text { articulations }\end{array}$} & Type II A & Type II B & \multicolumn{2}{|c|}{$\begin{array}{l}\text { Type II A F(i/c) or Type I B F(i/ } \\
\text { c) }\end{array}$} & $\begin{array}{l}\text { Type II A } 2 \text { F or Type II B } \\
2 \text { F }\end{array}$ & - \\
\hline & $\begin{array}{l}\text { Unilateral L5-S1 } \\
\text { accessory articulation }\end{array}$ & $\begin{array}{l}\text { Bilateral L5-S1 accessory } \\
\text { articulations }\end{array}$ & \multicolumn{2}{|c|}{$\begin{array}{l}\text { With presence of ipsi/contra } \\
\text { lateral rudimentary facet to the } \\
\text { side of the diarthrosis }\end{array}$} & $\begin{array}{l}\text { With presence of bilateral } \\
\text { rudimentary facets }\end{array}$ & \\
\hline \multirow{2}{*}{ Sacralisation** } & Type II A & Type III B & \multicolumn{2}{|l|}{ Type III C } & $\begin{array}{l}\text { Type III A F (i/c) or Type } \\
\text { III B F(i/c) or Type IIIC F }\end{array}$ & $\begin{array}{l}\text { Type III A } 2 \text { F or Type } \\
\text { III B } 2 \text { F or Type III C } \\
2 \text { F }\end{array}$ \\
\hline & $\begin{array}{l}\text { Unilateral L5-S1 } \\
\text { sacralisation }\end{array}$ & $\begin{array}{l}\text { Unilateral complete } \\
\text { sacralisation with } \\
\text { contralateral L5-S1 } \\
\text { pseudoarthrosis }\end{array}$ & \multicolumn{2}{|c|}{$\begin{array}{l}\text { Bilateral complete L5-S1 } \\
\text { sacralisation }\end{array}$} & $\begin{array}{l}\text { With presence of ipsi/contra } \\
\text { lateral rudiemntary facet to } \\
\text { the side of the sacralisation }\end{array}$ & $\begin{array}{l}\text { With presence of } \\
\text { bilateral rudimentary } \\
\text { facets }\end{array}$ \\
\hline \multirow[b]{2}{*}{ Lumbarisation** } & Type IV A & Type IV B & Type IV C & Type IV D & $\begin{array}{l}\text { Type IV A F(i/c) or Type IV } \\
\text { B F(i/c) or Type IV C F or } \\
\text { Type IV D F }\end{array}$ & $\begin{array}{l}\text { Type IV A } 2 \text { F or Type } \\
\text { IV B } 2 \text { F or Type IV C } \\
2 \text { F or Type IV D } 2 \text { F }\end{array}$ \\
\hline & $\begin{array}{l}\text { Incomplete/partial } \\
\text { lumbarisation of S1 as an } \\
\text { accessory S1-2 } \\
\text { articulation }\end{array}$ & $\begin{array}{l}\text { Unilateral complete } \\
\text { separation of S1 from } \\
\text { sacral mass }\end{array}$ & $\begin{array}{l}\text { Bilateral } \\
\text { S1-2 } \\
\text { accessory } \\
\text { articulation }\end{array}$ & $\begin{array}{l}\text { Complete } \\
\text { sacralisation with } \\
\text { residual four } \\
\text { segment sacrum }\end{array}$ & $\begin{array}{l}\text { With presence of ipsi/contra } \\
\text { lateral rudimentary facet to } \\
\text { the side of the diarthrosis }\end{array}$ & $\begin{array}{l}\text { With presence of } \\
\text { bilateral rudimentary } \\
\text { facets }\end{array}$ \\
\hline
\end{tabular}

*Southworth and Bersack. ${ }^{29}$ Modifications on the Castellvi's classifications are given in bold and italics. ** Situations with aymmetric augmentation of the auricular surface may be represented by adding the alphebets $\mathrm{SR}+$ or $\mathrm{SL}+$ for the corresponding right or the left sides. 
to the junction with mobilization of the left common iliac vein and inferior vena cava to the right of the midline is almost always required, similar to the approach to the L4-L5 disc. ${ }^{28}$

\section{Clinical Significance}

Low back pain in the presence of an LSTV was originally noted by Mario Bertolotti in 1917 and termed "Bertolotti's Syndrome". According to Quinlan et al., the prevalence of Bertolotti's syndrome is $4.6 \%$ in the general population and $11.4 \%$ in patients under the age of $30 .{ }^{29}$ Among 8280 patients seeking care for low back pain, Paik et al. found $10.6 \%$ had LSTV types II, III, or IV, with sacralization accounting for 5.3\% and lumbarization accounting for 5.3\%. ${ }^{5}$

Throughout the literature, the prevalence of LSTV in patients seeking care for low back pain ranges from 4.6\%-35.6\%.7, 29 Due to its wide prevalence, Quinlan et al. encourages physicians to consider Bertolotti's syndrome in the differential diagnosis for low back pain, especially in younger patients. ${ }^{29}$

The potential association between LSTV and low back pain has been debated since it was first described by Bertolotti almost a century ago. ${ }^{5}$ Among 4636 patients from the Osteoarthritis Initiative (OAI) cohort, Nardo et al. found that $53.9 \%$ of the patients without an LSTV reported low back pain. $46 \%$ of patients with a Type I and $40 \%$ of patients with a Type III LSTV reported low back pain, suggesting these anomalies might be a protective factor. $73 \%$ of patients with Type II and $66 \%$ of patients with Type IV LSTV reported low back pain. Type II and Type IV LSTV positively correlate with increased prevalence and greater severity of low back and buttock pain and with lower physical activity levels.9, 30 Tang et al.'s recent study of 928 individuals with LSTV supported the association between Type II LSTV with low back and gluteal pain, with respective odds ratios of 2.56 and 5.38. The odds ratios for low back and gluteal pain given the presence of a Type IV LSTV are 4.28 and 6.82 , respectively. ${ }^{8}$

Conversely, other authors believe that lumbosacral transitional segments are quite common in the general population and may not be seen with higher prevalence in patients reporting low back pain. ${ }^{7}$ In 1977,
Tini et al. found an insignificant difference between incidence of LSTV in patients with low back pain $(6.7 \%, \mathrm{n}=4000)$ and in the general population (5\%, $\mathrm{n}=1873) .{ }^{12}$ Several other studies found similar outcomes, concluding no difference in pain, disability level or neurological signs between individuals with and without an LSTV., ${ }^{7,31-33}$

A third opinion suggests that low back pain complaints might be worse, but not more frequent in the presence of an LSTV. Worse pain may result from the concentration of external stress on adjacent vertebral levels..$^{34,35}$ Among 881 young male patients, Taskaynatan et al. reported that the presence of an LSTV increased the severity of the patient's clinical picture and severity of pain. ${ }^{34}$ According to Yavuz et al., subjects with low back pain and no malformation reported an average pain level on the Visual Analog Scale for Pain (VAS) of 2.2 versus 4.8 in patients with low back pain and a transitional vertebra. ${ }^{35}$

\section{Structural Pathologies}

Bertolotti stated as early as 1917 that an LSTV may produce low back pain due to arthritic changes occurring at the site of pseudoarthrosis. ${ }^{36}$ Pain in the presence of an LSTV may also arise from disc herniation or degeneration, facet joint arthrosis, or spinal canal or foraminal stenosis. ${ }^{5}$ In 1989, Elster et al.'s radiographic study of 2000 patients suggested that the overall incidence of structural pathology, including significant disc protrusion, nerve root canal stenosis, spondylolysis, and sclerosis at "false joints" is not appreciably higher in LSTV patients than in patients without such vertebrae. ${ }^{37}$

Avimadje et al. found $52.7 \%$ of patients with a lumbar disc herniation also had an LSTV, while only $18.3 \%$ of the control group had an LSTV. ${ }^{38}$ Among patients with unilateral LSTV, $75.9 \%$ of the lumbar disc herniations occurred on the same side as the transitional vertebrae. ${ }^{39}$ Patients with a transitional vertebra experience disc herniation more frequently ( $17 \%$ vs. $11 \%)$ and at a younger age ( 35 years old vs. 59 years old) compared to patients without a transitional vertebra. ${ }^{32}$ Since age-related degenerative changes are common in the disc above a normal L5, the effect of transitional vertebrae may be obscured in middle age. 
The possible increased prevalence of disc protrusion or extrusion above the transitional vertebra could lead to radiating pain as a result of nerve root compression and chemical irritation. ${ }^{18}$

The probability of finding LSTV in patients with clinically significant spinal symptoms is 1.75 times higher than in patients with non-spinal complaints. This probability increases to 2.3 times among patients with symptoms severe enough to require an MRI and increases to 3.6 times among patients with last mobile disc herniation requiring discectomies. Therefore, it is possible to conclude that LSTV are more likely to be present in patients with clinically significant spinal symptoms and even more so in those operated on for disc herniation of the last mobile disc. ${ }^{40}$

Although the association between LSTV and pain continues to be debated, universal agreement throughout the literature describes an altered pattern of degenerative changes in patients with LSTV. Hypermobility and abnormal torque moments at the level immediately above the transitional vertebra and restricted movement between the L5 and S1 vertebra result in degenerative changes at the level above the anomalous articulation. ${ }^{18,20}$ Disc protrusion and/or extrusion occurs more often at the level supradjacent to the LSTV than at the same level in patients without an LSTV (45.3\% vs. 30.3\%). This is also true for disc degeneration ( $52.8 \%$ vs. $28 \%$ ), facet degeneration $(60.4 \%$ vs. $42.6 \%)$ and nerve root canal stenosis (52.8\% vs. $27.9 \%) .{ }^{41}$ Otani et al. reported $83 \%$ of patients with a disc herniation in the presence of an LSTV experienced symptoms arising from the last caudal mobile segment. Patients with disc herniation and no transitional vertebrae most frequently (59\%) had symptoms arising from the 2 nd last mobile segment. ${ }^{32}$

Disc bulge or herniation is exceedingly rare at the interspace below a transitional vertebra. ${ }^{20,23,32,37,39,42}$ Increasing the mechanical connection of a lumbosacral transitional vertebra protects the disc at the transitional level. The greater the osseous bridging at the transitional level, the more the transitional disc seems to be preserved from degeneration. ${ }^{43}$ The protective effect of transitional vertebrae acts stronger on the annulus fibrosus than on either the nuclear complex or endplates. Overall, the effect of transitional vertebrae on the adjacent discs may mimic the situation after a fusion operation when movement at one or more disc spaces is restricted in relation to other disc levels. ${ }^{18}$

The incidence of spinal stenosis and spondylolysis is not significantly higher in patients with an LSTV. ${ }^{37,44}$ However, the presence of an LSTV makes the magnitude of anterior slippage more severe. The greatest average slippage of L4 (19.3\%) occurs in sacralized patients. In lumbardized patients, the average slip of L4 is $14.5 \%$, while in control groups, the average slip of L4 is $11.4 \%{ }^{45}$

Unilateral LSTV result in asymmetrical biomechanical alterations. The side bearing the additional L5/S1 relationship supports a larger proportion of load, resulting in lateral tipping of the iliac crest and convexity of a scoliotic curve towards the side of the articulation. The sacroiliac joint on the side of the LSTV will increase the auricular area, probably resulting in increased loading of that joint, greater wear and irritation of the joint, greater fixation on exam, and increased one sided muscle activity. ${ }^{46}$ Asymmetry can cause early degenerative changes within the normal contralateral facet joint, giving rise to facet pain. ${ }^{47}$ Furthermore, asymmetrical movement may also influence disc degeneration. ${ }^{48}$

In Type II LSTV, the pseudoarticulation between the transverse process and the sacrum creates a "false joint", in which degenerative changes have occasionally been noted in clinical studies. ${ }^{46}$ The presence of sclerotic changes and osteophytes near the false joint imply slight motion in these vertebrae. Initial studies suggested that the side with degenerative changes in the articulation between the transverse process of the transitional vertebra and the pelvis do not correlate with the side of pain. ${ }^{37}$ More recently, however, Connolly et al. demonstrated that $80 \%$ of young patients with low back pain and an LSTV had high uptake on bone scintigraphy at the transverse-sacral articulation. The transverse-sacral articulation was the only abnormality in $63 \%$ of these low back pain patients, suggesting that localized stress at the articulation contributes to low back pain. ${ }^{49}$ 
S1 lumbarization has been implicated in compression neuropathy of the $S 1$ nerve root. ${ }^{13}$ The presence of an LSTV can result in pinching of a lumbar spinal nerve between the transverse process of the 5th lumbar vertebra and the sacral ala, a condition known as "Far-Out Syndrome." ${ }^{150-52}$ Osteoporosis resulting from "micromotion" at dysplastic facet joints at the level below the transitional vertebra can result in extraforaminal entrapment of the spinal nerve leading to radiculopathy. ${ }^{50}$ Neural compression by new bone formation below an LSTV occurs with a reported prevalence of $13 \%$ and can be symptomatic in up to $70 \%$ of these patients. ${ }^{53}$

\section{Imaging Lumbosacral}

\section{Transitional Vertebrae}

Most incorrect level surgical procedures occur in patients with numeric variant spines and/or LSTV. ${ }^{12}$ Spine physicians and radiologists must consider the possibility of numeric and morphological variations in lumbosacral images in order to avoid intervention or surgery at the incorrect level. ${ }^{42}$ To determine the location of a specific vertebral body on a sagittal radiograph, the last vertebra with a rectangular shape is generally considered to be L5, and then the vertebral bodies are numbered from the bottom to the top. However, in the presence of an LSTV the rectangular shaped last vertebra can be L4 or L6. ${ }^{5}$

The $30^{\circ}$ angled AP radiograph (Ferguson radiograph) serves as the reference standard method to detect LSTV (Figure 2). Sagittal images highlight transitional lumbosacral anatomy, such as "squaring" of the transitional vertebral body and reduced height of the transitional disc (Figure 3). Axial images depict pseudoarthrosis or fusion of the last lumbar vertebra with the sacrum. ${ }^{1}$

Standard AP radiographs demonstrate 76\%-84\% accuracy for LSTV detection and 53\%-58\% accuracy to classify LSTV. Diagnostic errors in identification of vertebral levels on sagittal lumbar MRI are also common. ${ }^{43}$ According to Tokgoz et al., $1.3 \%$ of patients with normal segmentation were misdiagnosed on MRI as having an LSTV, 35.1\% of the patients with an LSTV were misdiagnosed as having normal seg- mentation, and $60 \%$ of the patients with a correctly diagnosed LSTV had an incorrect number of vertebral levels. ${ }^{54}$

O'Driscoll et al. classified 4 types of lumbosacral junctions based on sagittal T1/T2 lumbar spine MRIs. In Type 1 no disc material is present. Type 2 denotes a small residual disc not extending for the whole AP diameter of the sacrum. Type 3 represents a well-formed disc extending for the whole AP diameter of the sacrum, while Type 4 is identical to Type 3 but with an abnormal upper sacral outline analogous to the "squaring" appearance on sagittal radiographs. Type 4 correlates with a fused LSTV (Castellvi Type III or Type IV). ${ }^{55}$ Furthermore, Desmond et al. utilized sagittal T2-weighted spinecho MRI in patients with LSTV to classify the transitional disc as Type 1 or Type 2 . A Type 1 transitional disc is smaller than the disc at the adjacent mobile segment, maintains T2-weighted signal intensity, lacks an intra-nuclear cleft, shows no evidence

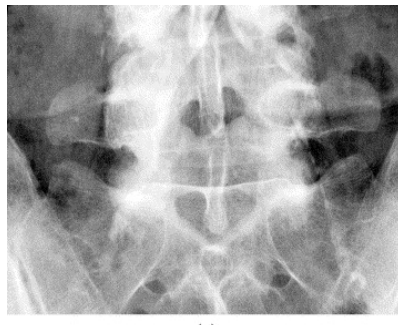

(a)

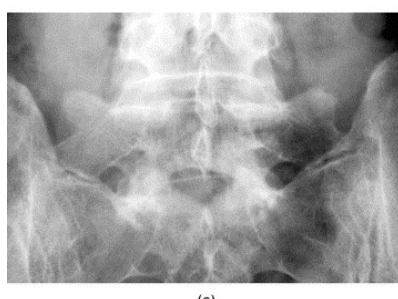

(c)

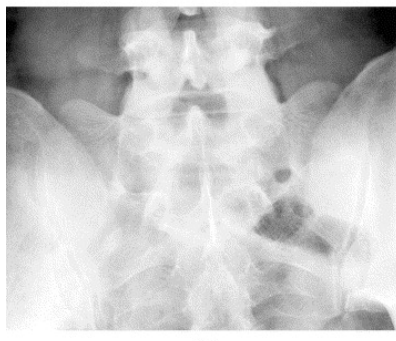

(e)

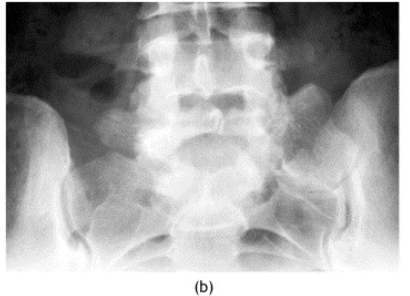

(b)
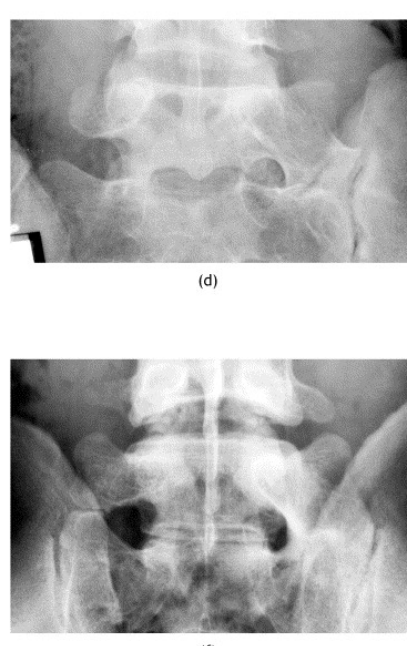

Fig. 2. Appearances of LSTV based on Castellvi et al. (a) Type 1b with bilaterally enlarged L5 transverse process but no articulation with the sacrum. (b) Type $2 a$ with unilateral pseudarthrosis. (c) Type $2 b$ with bilateral pseudarthroses. (d) Type 3 a with unilateral fusion of the enlarged transverse process to the sacral ala. (e) Type $3 b$ with bilateral fusion. (f)

Type 4 appearance with fusion on the left side and a pseudarthrosis on the right. $^{1}$

Downloaded from http://ijssurgery.com/ by guest on April 26, 2023 
of fusion between anterior vertebral body endplates and associates with the pseudoarthrosis of the transverse vertebra of the LSTV to the sacrum. A Type 2 transitional disc is smaller than Type 1, maintains its signal intensity, lacks an intra-nuclear cleft, shows evidence of anterior endplate fusion and concave endplates to the disc and is associated with the complete fusion of the LSTV to the sacrum. ${ }^{56}$

LSTV patients frequently demonstrate exaggerated lumbar lordotic curvature and a lack of sharp angulations at the lumbosacral junction on mid-sagittal MRI. An angle formed by a line parallel to the superior surface of the sacrum and a line perpendicular to the axis of the scan table on mid-sagittal T2-weighted MRI $>39.8^{\circ}$ predicts the presence of an LSTV with $80 \%$ sensitivity and $80 \%$ specificity. In addition, an angle formed by a line parallel to the superior endplate of the L3 vertebra and a line parallel to the superior surface of the sacrum $>35.9^{\circ}$ predicts the pres-

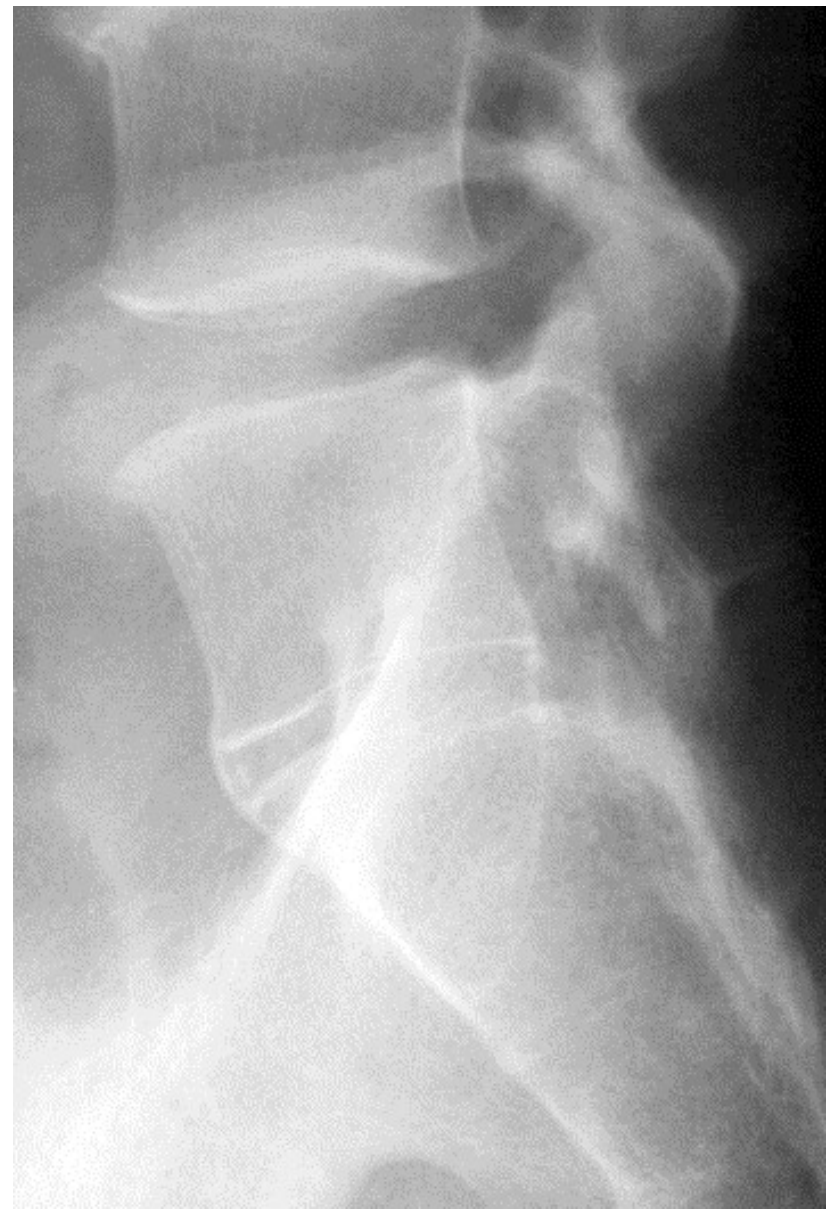

Fig. 3. Lateral radiograph of the lumbosacral junction showing the typical appearance of an LSTV with "squaring" of the transitional vertebral body and reduced height of the transitional disc.' ence of an LSTV with $80 \%$ sensitivity and $54 \%$ specificity. ${ }^{48}$ It should be noted that the magnitude of the angle formed between the lumbosacral junction vertebral endplates (lumbosacral intervertebral disc angle) is not a useful diagnostic tool. ${ }^{57}$

Farshad et al. advocate measuring the differences per segment of the vertical mid-vertebral angle (DiffVMVA) and the vertical anterior vertebral angle (Diff-VAVA) of the three most caudal segments of the lumbar spine to simply and reliably identify LSTV. A Diff-VMVA of $\leq+10^{\circ}$ identified type III and IV LSTV with a sensitivity of $100 \%$ and a specificity of $89 \%$ on MRI and with a sensitivity of $94 \%$ and a specificity of $74 \%$ on lateral radiograph. In terms of Diff-VAVA, a sensitivity of $100 \%$ and a specificity of $76 \%$ were achieved with a cut-off value of $28^{\circ} . .^{58}$

Paik et al. suggest routinely adding sagittal T2W images to the lumbar MRI protocol and thoracolumbar sagittal T2W images to the cervical MRI protocol. In addition to screening of coexisting lesions, wholespine sagittal T2W images play an essential role in accurate vertebral numbering. Numbering caudally from $\mathrm{C} 2$ on whole-spine MR images and utilizing morphological classification by Castellvi enables proper identification of both numeric and morphological vertebral variations (Figure 4$){ }^{5}$ Plain radiographs of the thoracolumbar junction enable hypoplastic true ribs to be differentiated from large transverse processes and therefore enable correct identification of the L1 vertebral body. ${ }^{22,57}$

Milicic et al. suggest that the suspicion of an LSTV in a child requires sagittal images of the sacrum and coccygeal bone on $\mathrm{T} 2$ weighted sequence in addition to MR imaging scans of the lumbosacral spine. The clinician should count up from S5 and precisely determine S1. Determination of S1 enables detection of the L5 and, in turn, all other vertebrae..$^{59}$

Paraspinal structures in positions outside their frequent location may signify the presence of a transitional vertebra. On sagittal images, the aortic bifurcation, IVC confluence, right renal artery, celiac trunk, and superior mesenteric artery root are located 1-3 levels more caudal than normal in the case of lumbarization, and 1-3 levels more cephalic than normal 
in the case of sacralization..$^{60}$ Nonspinal anatomic landmarks are problematic, however, because of their variable location and potential changes with age. ${ }^{57}$

Although Hughes et al. concluded that the iliolumbar ligament always arises from L5, ${ }^{61}$ a more accurate conclusion of their research would be that the iliolumbar ligament arises from the last lumbar vertebra, which could be L4, L5, or L6, depending on the segmentation of the spine..$^{2}$ Therefore, the iliolumbar ligament does not allow for absolute numbering of the vertebral column and the iliolumbar ligament is not a consistent tool to number the spine, as it does not always indicate the L5 level. ${ }^{57}$

An anomalous number of presacral vertebrae is $7 \mathrm{x}$ more likely in the presence of an LSTV. In addition, the presence of an LSTV is associated with a higher incidence of a concomitant thoracolumbar TV (TLTV) and vice versa. Identification of an LSTV should prompt additional imaging to verify numbering, particularly if an intervention is contemplated. Clinicians should remember that no landmark is con-

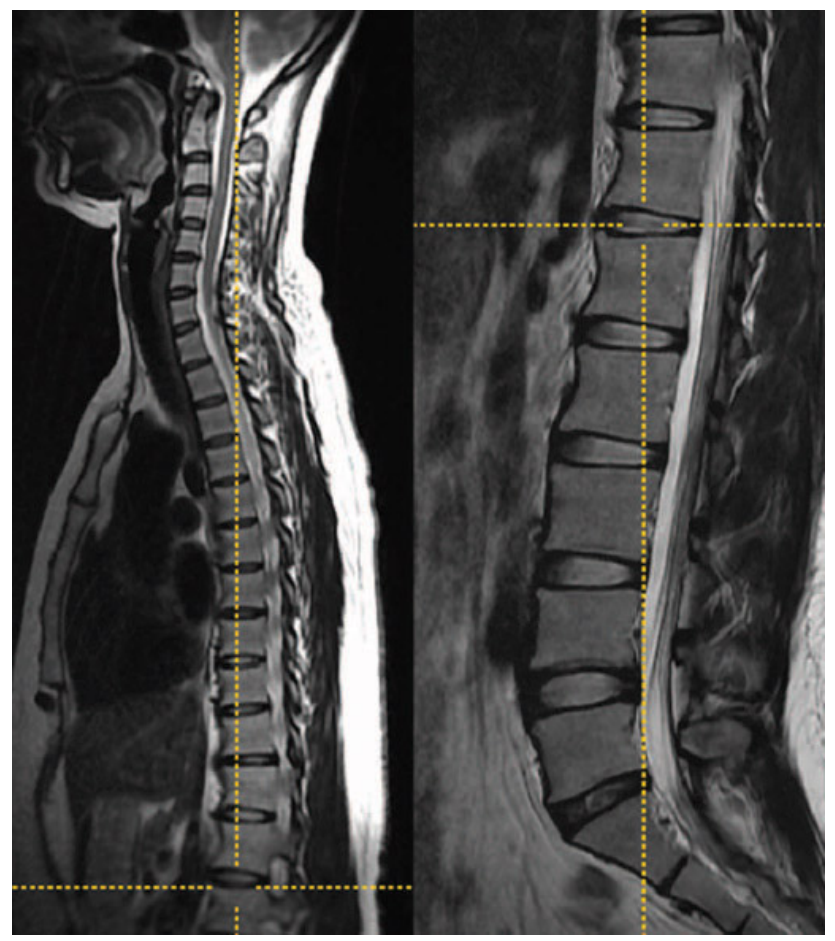

Fig. 4. A case of $L 6$ vertebra with type lla transition. Left, T2-weighted sagittal cervicothoracic and (right) lumbar images in the cross-referencing mode of the picture archiving and communication system. This simultaneously demonstrates the marker at the T12-L1 disc space. Counting the vertebral levels caudally from $\mathrm{C} 2$ reveals this patient to have 25 presacral vertebrae or 6 lumbar vertebrae. ${ }^{5}$ sistently reliable, so an explicit statement regarding how the lumbosacral junction was determined must be made in the imaging report. ${ }^{57}$

\section{Diagnosis And Treatment Of Bertolotti'S Syndrome}

Low back pain is a prevalent problem with multiple causes. Approximately $80 \%$ of adults seek a physician's help for low back pain at some point in their lives. Given the wide prevalence of LSTV, it is important that low back pain in the presence of an LSTV is not automatically attributed to the radiographic finding of an enlarged transverse process. ${ }^{63}$ A diagnosis of Bertolotti's syndrome should be cautiously considered with appropriate patient history, imaging studies, and diagnostic injections.$^{64}$ As with other causes of low back pain, the initial treatment of symptomatic LSTV is clinical, including a combination of NSAIDS and rehabilitative physical therapy. ${ }^{65}$ There is a lack of consensus, however, regarding the treatment of this condition, and the number of studies and case reports in the literature reporting on the diagnosis and outcomes of patients with symptomatic LSTV is sparse. ${ }^{64,66}$

The literature includes 4 reports of either chiropractic management or physical therapy to treat symptomatic LSTV. Muir et al. reported 2 patients with Castellvi Type IIa LSTV presenting with limited ipsilateral flexion coincided with ipsilateral muscular symptomatology similar to piriformis syndrome. 1 patient experienced 70\% improvement in symptoms after 2 weeks of spinal manipulation, soft tissue therapies, exercise and stretching. The other patient reported improvement in pain and perceived mobility after 4 weeks of similar treatment. ${ }^{66} 2$ additional case reports described patients with low back pain and an LSTV that resolved following spinal manipulation, stretching and exercise. ${ }^{67,68}$ The authors proposed that the decreased mobility at the L5/S1 junction brought on by an LSTV results in biomechanical changes and altered weight distribution at this level. These changes increase stress on the muscles in the region of the sacroiliac and lumbosacral junction on the affected side. Therefore, the authors indicated a role for conservative care in patients with LSTV, not 
to relieve pressure on an impinged nerve, but instead to address muscular alterations in the lumbopelvic musculature. ${ }^{66}$

Because of its simplicity, low expense, and wide availability, functional flexion-extension radiography is the most thoroughly studied and the most widely used method in the imaging diagnosis of lumbar intervertebral instability. Flexion-extension lateral views allow measurement of the sagittal translation of a vertebra with respect to the underlying one and the amount of vertebral rotation in the sagittal plane.$^{69}$ According to Little et al., strengthening and stabilizing exercises probably have moderate benefit on patients with low back pain associated with abnormal movement patterns identified on dynamic $x$-ray studies. ${ }^{70}$ Lessons in the Alexander technique offer an individualized approach to develop skills that help patients recognize, understand, and avoid poor habits affecting postural tone and neuromuscular coordination. Little et al. randomized 579 patients with recurrent low back pain to normal care, to 6 Alexander technique lessons, or to 24 Alexander lessons. 24 lessons in the Alexander technique taught by registered teachers provided long-term benefits for patients with chronic or recurrent low back pain. The authors reported changes in postural tone and changes in load and position. These findings supported the hypothesis that the Alexander technique could potentially reduce back pain by limiting muscle spasm, strengthening postural muscles, improving coordination and flexibility, and decompressing the spine. ${ }^{70}$ Several studies have also examined the effects of Pilates method in people with chronic low back pain. The literature defines Pilates method as a mind-body exercise that focuses on core stability, muscle control, breathing, strength, flexibility, and posture. Pilates method involves conscious use of trunk muscles to stabilize the pelvic-lumbar region. The current consensus suggests that Pilates methodbased exercises are more effective than no treatment or minimal physical exercise interventions in the management of chronic low back pain. ${ }^{71}$

L4/5 joint radiofrequency sensory ablation has been reported to provide $100 \%$ relief of buttock pain for 16 months in 1 patient with an LSTV. ${ }^{72}$ Additionally, Endo et al. reported immediate disappearance of low back pain in a patient with an LSTV following electric denervation of the space between the transverse process of the 5th lumbar vertebra and the sacral ala. The authors advocated electric denervation as a minimally invasive and potentially effective method for pain eradication. ${ }^{73}$

Injections of steroids or local anesthetics into the transverse process pseudoarticulation site can be both diagnostic and provide immediate, albeit temporary, pain relief..$^{64}$ Almeida et al. advocated performing these blocks with a minimal amount of anesthetic delivered precisely to the point of interest. ${ }^{65}$ Mitra et al. reported an improved Oswestry score from 33 to 26 in a 64-year-old female with a Type IIb LSTV 1 month following a local anesthetic and corticosteroid injection administered to the transverse process-ilium articulation. ${ }^{74}$ In a retrospective study of 12 patients with unilateral lumbo-sacral anomalous articulation with same side low back or buttock pain, 9 patients reported a 50\% decrease in pain after 1 month. 7 out of 8 patients who were re-evaluated 24 months later improved or were symptom free. ${ }^{38}$ Marks et al. reported that 7 out of 10 patients with chronic low back pain and an anomalous lumbosacral articulation obtained worthwhile relief after steroid injection of the anomalous lumbosacral articulation and 1 patient remained pain free at 24 months. ${ }^{75}$

A diagnostic injection at the pseudoarticulation site not only provides pain relief but also helps determine if the LSTV is a significant source of the patient's low back pain and radicular symptoms. Li et al. relied on patient response to injection as an exclusionary test for surgery. Specifically, if the injection did not provide relief, the patient was not considered a surgical candidate. Discography may be useful if the disc above the transitional vertebra is thought to be the source of the pain. ${ }^{63}$

Bone scintigraphy complements the evaluation of patients with low back pain thought to arise from LSTV articulations. LSTV articulations increase uptake on bone scintigraphy secondary to degeneration and metabolic activity of the anomalous articulation (Figure 5). Pekindil et al. evaluated 28 patients in whom a lumbosacral transitional vertebral articulation had been identified radiographically. On planar 
imaging, normal-to-minimally and normal-tomoderately non-focal increased uptake was observed in patients without degenerative changes and with degenerative changes, respectively. The authors stated that when increased uptake is seen on the upper $1 / 2$ to $1 / 3$ part of the sacroiliac joint on planar images, this should not be mistaken for sacroiliac joint disease and degenerative LSTV articulations should especially be considered in the differential diagnosis. On SPECT imaging, the patients who had no degenerative changes at the anomalous articulation had non-focal mild uptake. However, in symptomatic patients with degenerative changes in which no cause was found for low back pain by clinical, laboratory, $\mathrm{CT}$ and bone SPECT examinations, there was focal markedly increased uptake on SPECT imaging. The authors advocated that focal, markedly increased uptake may show the metabolically active degenerative changes of LSTV articulation and may help to reveal pain arising from LSTV articulations. ${ }^{76}$

Almeida et al. proposed a diagnostic-therapeutic algorithm based on the clinical and surgical experience they acquired treating 5 patients with low back pain in the presence of an LSTV (Figure 6). These 5 patients did not improve with clinical treatment, including non-steroidal anti-inflammatory drugs (NSAIDS), physiotherapy and physical exercises.
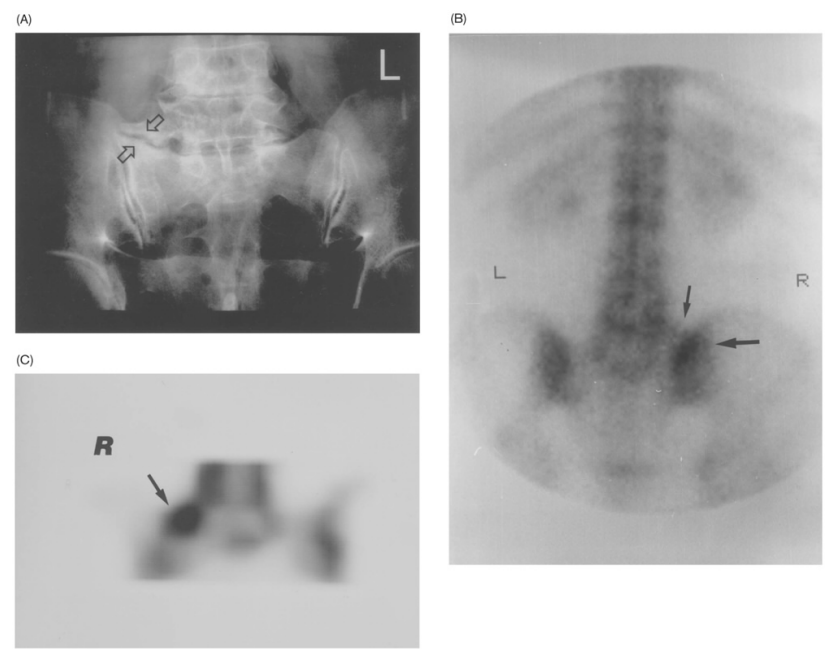

Fig. 5. Female patient age 62 with low back pain and with degenerative type IIA LSTV articulation (arrows) on the right side on plain film. (B) Non-focal, moderately increased uptake (large arrow) on the upper sacroiliac joint area at the planar scan. Note also the non-focal, minimal, tracer activity (small arrow) corresponding to the right enlarged transverse process. (C) Coronal SPECT image demonstrates focal, markedly increased activity (arrow) located in the degenerative anomalous articulation area.

This patient was diagnosed as having active degenerative disease. ${ }^{63}$
The patients were submitted to an anesthetic block at the contact of the mega-apophysis with the sacrum, which provided temporary pain relief in all 5 patients. Thereafter, they underwent radiofrequency neurolysis, whereby 3 patients experienced only a partial control of the pain and two experienced significant improvement. The latter 2 patients underwent mega-apophysis surgical resection and achieved complete resolution of symptoms during the 1 year follow up. The authors recommended considering mega-apophysis surgical resection for the sub-group of patients with low back pain and LSTV who fail conservative treatment, but experience temporary relief with anesthetic block. Other associated causes of low back pain should be considered if anesthetic block of the anomalous articulation does not provide pain relief. ${ }^{65}$

Jonsson et al. described 11 patients with low back pain ipsilateral to an LSTV. None of the patients had signs or symptoms of lumbar nerve root compression. 9 out of the 10 patients who had an injection of local anesthetic into the anomalous articulation experienced pain reduction or alleviation. These $9 \mathrm{pa}-$ tients subsequently underwent resection of the abnormal joint. At 6 to 42 months postoperatively, 7

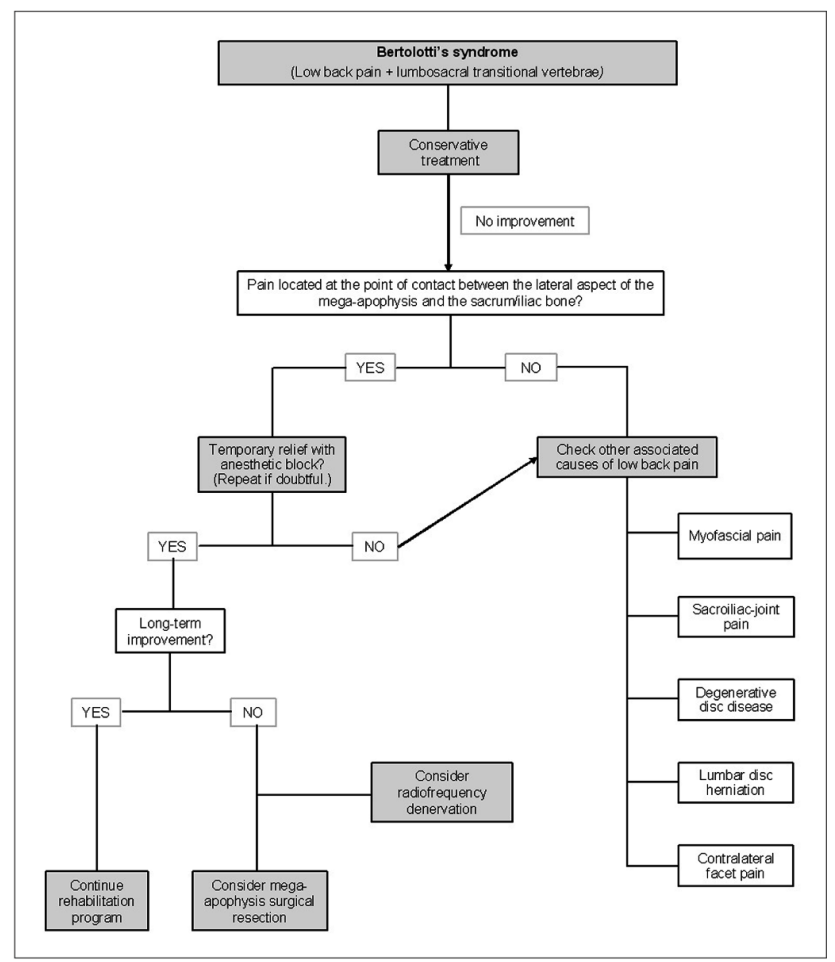

Fig. 6. Proposed diagnostic-therapeutic algorithm for evaluation and treatment of Bertolotti's Syndrome. ${ }^{65}$ 
patients reported total alleviation of pain, and 2 experienced significant improvement. ${ }^{77}$

Santavirta et al. surgically treated 16 patients with radiographically diagnosed LSTV and chronic, persistent low back pain with either posterolateral fusion or resection of the transitional articulation. 10 of the 16 operatively treated patients showed improvement of their low back pain. The results were similar in the group treated with fusion and in the group treated with resection. 11 patients had persisting episodes of sciatica (versus 13 preoperatively). At follow-up the first disc above the fused segment was found to be degenerative in 7 out of 8 cases, and in the group treated with resection the first disc above the transitional vertebra was degenerated in 5 out of 8 cases. 3 patients from each group were treated with second operations. Compared to 16 conservatively treated controls, the operatively treated patients had slightly better Oswestry pain scores, however the total Oswestry disability scale scores did not differ. Given that the results of surgical treatment were only slightly better than conservative treatment, the authors suggested operative treatment in only very select patients who should be carefully examined for disc pathology. The authors recommended resection if the patient's pain can be definitively attributed to the transitional joint, conservative treatment fails, and no disc pathology can be detected. Posterolateral fusion may be considered if the transitional disc is degenerated, and the disc above the transitional vertebra is intact. ${ }^{78}$

Ugokwe et al. achieved 97\% pain resolution in one patient with a minimally invasive approach to resect an enlarged transverse process and the accompanying anomalous pseudoarticulation at the L5 level. The same authors published the results of seven patients who underwent minimally invasive paramedian tubular-based resection of symptomatic LSTV. The mean age at the time of surgery was 43.3 years and the mean age at diagnosis of Bertolotti's syndrome was 40.2 years. The median duration of low-back pain and/or radicular symptoms was 8 years prior to surgery. 3 of 7 patients reported complete resolution of low back pain, 2 of 7 patients had reduced lowback pain, and 2 patients experienced initial relief but return of low-back pain at 1 and 4 years postopera- tively. 3 of the 6 patients with radicular pain had complete relief of this symptom. ${ }^{64}$

Only 8 cases of impingement of a nerve root by a bony spur at the articulation between the transverse process of a transitional vertebra and the sacrum have been reported in the literature. 6 of these patients underwent surgical intervention. In a patient described by Abe et al, MRI revealed mild degenerative changes with minimal posterior disc bulging and impingement of the left L5 nerve root by bony spur formation at the anterior exit zone of the nerve root foramen below a transitional vertebra. Selective nerve root sheath infiltration of the left L5 nerve root was performed. The patient's pain was reproduced over the same area of the left leg during insertion of the needle. Immediately after the injection of a $2-\mathrm{mL}$ solution of $2 \%$ lidocaine hydrochloride with contrast, these symptoms completely disappeared. Selective radiculography demonstrated foraminal impingement of the nerve root between the lateral bony spur and the medial intervertebral disc. Given that 3 lesions demonstrated by MRI could have been the symptomatic lesion, selective radiculography proved useful in differentiating the symptomatic lesion of the nerve root. The authors then performed an anterior decompression (left-sided, muscle splitting, extra peritoneal approach/Fraser's Incision), which resulted in complete resolution of back pain and numbness by the follow-up examination 1 year after surgery. ${ }^{51}$ Kikuchi et al reported two additional cases of anterior decompression for far-out syndrome below a transitional vertebra. Anterior decompression was performed for both cases using a Fraser incision and resulted in successful resolution of symptoms. The authors advocated anterior decompression for cases of far-out syndrome refractory to selective nerve root block, explaining that this approach allows for a more complete decompression in the context of entrapment more anterior of the exit zone of the foramen compared to other pathologies. The authors stated that it would have been difficult to obtain a wide, well-illuminated, and dry surgical field from the posterior approach. ${ }^{51,79}$

Ichihara et al. however, reported no difficulty with decompression using a posterior approach for one patient who obtained good relief of radicular pain.

Downloaded from http://ijssurgery.com/ by guest on April 26, 2023 
The authors described posterior decompression as an easy, safe, and useful treatment for radicular pain caused by an L 5 nerve far-out syndrome when conservative treatments fail to obtain good relief. ${ }^{52} \mathrm{We}$ ber and Ernestus reported a patient with radicular pain and a unilateral anomaly of the right transverse process of L5 resulting in foraminal stenosis of the L5 spinal nerve and, especially, entrapment outside the foramen between the large transverse process of the sacral ala. Following foraminal and extraforaminal decompression of the nerve via an extraforaminal approach, the patient reported no radicular or lumbar pain at 12 months follow up..$^{50}$ Miyoshi et al. employed selective radiculography and nerve root block followed by computed tomography to highlight foraminal entrapment of the L5 nerve root via osteophytes below a transitional vertebra. The patient underwent posterior decompression by resection of the osteophytes using an operating microscope and the patient experienced good relief of radicular pain. The authors emphasized that selective radiculography is the most reliable modality to diagnose far-out entrapment of the L5 nerve root and that CT in combination with radiculography clearly demonstrates not only the degree of L5 nerve root impingement, but also the etiology of the L5 nerve root compression. ${ }^{80}$

Shibayama et al. described a patient with an enlarged right-sided transverse process at L6, moderate compression of the dural sac on the right side at L5-6, and mild compression of the right L6 spinal nerve. Although microendoscopic decompression of the spinal canal provided little relief, extraforaminal decompression of right L6 relieved both low back pain and sciatica. The authors suggested that intractable sciatica secondary to an enlarged transverse process could arise from impingement of the nerve root extraforaminaly rather than between the transverse process and the sacrum..$^{81}$ It is often difficult to differentiate symptomatic and asymptomatic extraforaminal stenosis secondary to osteophyte formation on conventional MRI alone. With the use of 3D MR lumbosacral radiculography, Byun et al. associated indentation or swelling at the L5 nerve root with symptomatic extraforaminal stenosis. These radiographic findings were distinctively absent in cases of asymptomatic extraforaminal stenosis. ${ }^{82}$
Resection of a right-sided unilateral anomalous lumbosacral articulation provided $90 \%$ relief of left low back pain and complete relief of left leg symptoms in 1 patient with a contralateral symptomatic L6-S1 facet joint. The authors suggested that the patient's pain was not associated with the anomalous articulation itself, but was probably due to additional stress placed on the normal contralateral joint. In this case, pain relief resulted from reduced stress on the symptomatic facet. ${ }^{47}$

\section{Conclusions}

Although Bertolotti's syndrome was first described nearly a century ago, debate continues regarding the prevalence, clinical significance, radiographic identification and treatment of symptomatic LSTV. While early studies depicted LSTV as a rare anatomical anomaly, studies incorporating revised definitions and improved imaging techniques suggest LSTV may be present in up to $35.9 \%$ percent of the general population. $^{7}$

The formation of an LSTV may serve as a compensatory response to inadequate load bearing capacity of the sacrum ${ }^{13}$ or spinal instability secondary to weak iliolumbar ligaments. ${ }^{20}$ The resulting morphological alterations have important implications on spine surgery. Most incorrect level surgical procedures occur in patients with numeric variant spines or LSTV. ${ }^{12}$ Changes of neural arch elements and auricular surfaces complicate the placement of pedicle screws in an LSTV. ${ }^{14,16}$ Lumbar interbody fusion at the junction above a fixed transitional level requires an alternative approach due to migration of neuronal anatomy within the psoas muscle and the more caudal location of the junction between the common iliac veins and inferior vena cava. ${ }^{27,28}$

Spine physicians must identify the presence of LSTV prior to surgical intervention. The Ferguson radiograph serves as the reference standard method to detect LSTV, though diagnostic errors and inaccurate identification of vertebral levels on both standard radiographs and MRI are common. ${ }^{43}$ The use of whole-spine images as well as geometric relationships between the sacrum and lumbar vertebra help increase accuracy. ${ }^{5,57,58}$ 
Investigations regarding the association between LSTV and clinically significant low back pain have yielded inconsistent and conflicting results.

Throughout the literature, Type II and Type IV are most consistently associated with back and buttock pain and decreased physical activity levels. ${ }^{9,30}$ Symptoms associated with LSTV Type II potentially arise from degenerative changes in the pseudoarticulation between the transverse process and the pelvis. ${ }^{46}$ The formation of osteophytes in these "false joints" can cause nerve root compression..$^{53}$ Disc herniation and degeneration almost always occur at the level supradjacent to the LSTV and may occur more frequently and at younger ages than in individuals without an LSTV. $^{18,20,32}$

The pathophysiology of Bertolotti's syndrome remains obscure and there is no consensus about the most appropriate therapy for each patient. Due to its multifactorial causes and the common findings of low back pain in the general population, it is essential to differentiate low back pain caused by transverse mega-apophysis contact with the sacrum from other sources of back pain in patients with LSTV. ${ }^{65} \mathrm{~A}$ positive radionuclide study along with a positive effect from a local injection is most helpful in establishing the diagnosis of a symptomatic pseudoarticulation. Meanwhile, selective radiculography serves as a reliable modality to diagnose far-out entrapment of the L5 nerve root. CT in combination with radiculography helps identify the point of impingement and the etiology of the L5 nerve root compression. ${ }^{80}$

The literature contains a total of 43 cases of surgical intervention for symptomatic LSTV. 27 patients were treated with resection, 8 underwent fusion, 6 patients were treated for far-out syndrome, and the remaining 2 cases involved surgical intervention for extraforaminal nerve root impingement or pain contralateral to the LSTV. ${ }^{47,50-52,63,77-81}$ Only Santavirta et al. compared the surgically treated patients to a conservative treatment control group. The results of surgical treatment were only slightly better. The authors of these cases advocated for operative treatment of Bertolotti's syndrome in very select patients whose refractory pain is definitively attributed to the transitional vertebrae. ${ }^{78}$ Given the paucity of evidence, further investigations with larger patient cohorts are needed to better understand the association between the anomalous transverse process and low back pain that occurs with LSTV and to better demonstrate the effectiveness of surgical intervention. ${ }^{64}$

\section{References}

1. Hughes RJ, Saifuddin A. Imaging of lumbosacral transitional vertebrae. Clinical radiology.

2004;59(11):984-91.

2. Mahato NK. Redefining lumbosacral transitional vertebrae (LSTV) classification: integrating the full spectrum of morphological alterations in a biomechanical continuum. Medical hypotheses. 2013;81(1):76-81.

3. Konin GP, Walz DM. Lumbosacral transitional vertebrae: classification, imaging findings, and clinical relevance. AJNR American journal of neuroradiology. 2010;31(10):1778-86.

4. Mahato NK. Complexity of neutral zones, lumbar stability and subsystem adaptations: probable alterations in lumbosacral transitional vertebrae (LSTV) subtypes. Medical hypotheses. 2013;80(1):61-4.

5. Paik NC, Lim CS, Jang HS. Numeric and morphological verification of lumbosacral segments in 8280 consecutive patients. Spine.

2013;38(10):E573-8.

6. Castellvi AE, Goldstein LA, Chan DP. Lumbosacral transitional vertebrae and their relationship with lumbar extradural defects. Spine.

1984;9(5):493-5.

7. Apazidis A, Ricart PA, Diefenbach CM, Spivak JM. The prevalence of transitional vertebrae in the lumbar spine. The spine journal : official journal of the North American Spine Society.

2011;11(9):858-62.

8. Tang M, Yang XF, Yang SW, Han P, Ma YM, Yu $\mathrm{H}$, et al. Lumbosacral transitional vertebra in a population-based study of 5860 individuals: Prevalence and relationship to low back pain. European journal of radiology. 2014;83(9):1679-82.

9. Nardo L, Alizai H, Virayavanich W, Liu F, Hernandez A, Lynch JA, et al. Lumbosacral transitional vertebrae: association with low back pain. Radiology. 2012;265(2):497-503.

10. Dzupa V, Slepanek M, Striz M, Krbec M,

Downloaded from http://ijssurgery.com/ by guest on April 26, 2023 
Chmelova J, Kachlik D, et al. Developmental malformations in the area of the lumbosacral transitional vertebrae and sacrum: differences in gender and left/ right distribution. Surgical and radiologic anatomy : SRA. 2013.

11. Mahato NK. Relationship of sacral articular surfaces and gender with occurrence of lumbosacral transitional vertebrae. The spine journal : official journal of the North American Spine Society. 2011;11(10):961-5.

12. Tini $P G$, Wieser $C$, Zinn WM. The transitional vertebra of the lumbosacral spine: its radiological classification, incidence, prevalence, and clinical significance. Rheumatology and rehabilitation.

1977;16(3):180-5.

13. Mahato NK. Morphological traits in sacra associated with complete and partial lumbarization of first sacral segment. The spine journal : official journal of the North American Spine Society.

2010;10(10):910-5.

14. Mahato NK. Pedicular anatomy of the first sacral segment in transitional variations of the lumbo-sacral junction. Spine. 2011;36(18):E1187-92. 15. Mahato NK. Pars inter-articularis and laminar morphology of the terminal lumbar vertebra in lumbosacral transitional variations. North American journal of medical sciences. 2013;5(6):357-61.

16. Mahato NK. Trabecular bone structure in lumbosacral transitional vertebrae: distribution and densities across sagittal vertebral body segments. The spine journal : official journal of the North American Spine Society. 2013;13(8):932-7.

17. Mahato NK. Facet dimensions, orientation, and symmetry at L5-S1 junction in lumbosacral transitional States. Spine. 2011;36(9):E569-73.

18. Luoma K, Vehmas T, Raininko R, Luukkonen R, Riihimaki $H$. Lumbosacral transitional vertebra: relation to disc degeneration and low back pain. Spine. 2004;29(2):200-5.

19. Hsieh CY, Vanderford JD, Moreau SR, Prong T. Lumbosacral transitional segments: classification, prevalence, and effect on disk height. Journal of manipulative and physiological therapeutics. 2000;23(7):483-9.

20. Aihara T, Takahashi K, Ogasawara A, Itadera E, Ono Y, Moriya $\mathrm{H}$. Intervertebral disc degeneration associated with lumbosacral transitional vertebrae: a clinical and anatomical study. The Journal of bone and joint surgery British volume. 2005;87(5):687-91. 21. Morimoto T, Sonohata M, Kitajima M, Konishi $\mathrm{H}$, Otani K, Kikuchi S, et al. The termination level of the conus medullaris and lumbosacral transitional vertebrae. Journal of orthopaedic science : official journal of the Japanese Orthopaedic Association. 2013;18(6):878-84.

22. McCulloch JA, Waddell G. Variation of the lumbosacral myotomes with bony segmental anomalies. The Journal of bone and joint surgery British volume. 1980;62-b(4):475-80.

23. Chang HS, Nakagawa $H$. Altered function of lumbar nerve roots in patients with transitional lumbosacral vertebrae. Spine. 2004;29(15):1632-5; discussion 5.

24. Kim YH, Lee PB, Lee CJ, Lee SC, Kim YC, Huh J. Dermatome variation of lumbosacral nerve roots in patients with transitional lumbosacral vertebrae. Anesthesia and analgesia. 2008;106(4):1279-83, table of contents.

25. Hinterdorfer P, Parsaei B, Stieglbauer K, Sonnberger M, Fischer J, Wurm G. Segmental innervation in lumbosacral transitional vertebrae (LSTV): a comparative clinical and intraoperative EMG study. Journal of neurology, neurosurgery, and psychiatry. 2010;81(7):734-41.

26. Seyfert $S$. Dermatome variations in patients with transitional vertebrae. Journal of neurology, neurosurgery, and psychiatry. 1997;63(6):801-3. 27. Smith WD, Youssef JA, Christian G, Serrano S, Hyde JA. Lumbarized sacrum as a relative contraindication for lateral transpsoas interbody fusion at L5-6. Journal of spinal disorders \& techniques. 2012;25(5):285-91.

28. Weiner BK, Walker M, Fraser RD. Vascular anatomy anterior to lumbosacral transitional vertebrae and implications for anterior lumbar interbody fusion. The spine journal : official journal of the North American Spine Society. 2001;1(6):442-4. 29. Quinlan JF, Duke D, Eustace S. Bertolotti's syndrome. A cause of back pain in young people. The Journal of bone and joint surgery British volume. 2006;88(9):1183-6.

30. Dai L. Lumbosacral transitional vertebrae and low back pain. Bulletin (Hospital for Joint Diseases (New York, NY)). 1999;58(4):191-3. 
31. Peterson CK, Bolton J, Hsu W, Wood A. A cross-sectional study comparing pain and disability levels in patients with low back pain with and without transitional lumbosacral vertebrae. Journal of manipulative and physiological therapeutics. 2005;28(8):570-4.

32. Otani K, Konno S, Kikuchi S. Lumbosacral transitional vertebrae and nerve-root symptoms. The Journal of bone and joint surgery British volume. 2001;83(8):1137-40.

33. Secer M, Muradov JM, Dalgic A. Evaluation of congenital lumbosacral malformations and neurological findings in patients with low back pain. Turkish neurosurgery. 2009;19(2):145-8.

34. Taskaynatan MA, Izci Y, Ozgul A, Hazneci B, Dursun H, Kalyon TA. Clinical significance of congenital lumbosacral malformations in young male population with prolonged low back pain. Spine. 2005;30(8):E210-3.

35. Yavuz U, Bayhan AI, Beng K, Emrem K, Uzun $M$. Low back complaints worse, but not more frequent in subjects with congenital lumbosacral malformations: a study on 5000 recruits. Acta orthopaedica Belgica. 2012;78(5):668-71.

36. Bertolotti M. Contributo alla conoscenza dei vizi di differenziazione regionale del rachide con speciale riguardo all assimilazione sacrale della v. lombare. Radiologiqu Medica. 1917(4):113-44.

37. Elster AD. Bertolotti's syndrome revisited. Transitional vertebrae of the lumbar spine. Spine. 1989;14(12):1373-7.

38. Avimadje M, Goupille P, Jeannou J, Gouthiere $\mathrm{C}$, Valat JP. Can an anomalous lumbo-sacral or lumbo-iliac articulation cause low back pain? A retrospective study of 12 cases. Revue du rhumatisme (English ed). 1999;66(1):35-9.

39. Li JG, Yang HL, Niu GQ. [The relationship between lumbosacral transitional vertebra and the lumbar disc herniation]. Zhonghua wai ke za zhi [Chinese journal of surgery]. 2006;44(8):556-8.

40. Sekharappa V, Amritanand R, Krishnan V, David KS. Lumbosacral transition vertebra: prevalence and its significance. Asian spine journal. 2014;8(1):51-8.

41. Vergauwen S, Parizel PM, van Breusegem L, Van Goethem JW, Nackaerts Y, Van den Hauwe L, et al. Distribution and incidence of degenerative spine changes in patients with a lumbo-sacral transitional vertebra. European spine journal : official publication of the European Spine Society, the European Spinal Deformity Society, and the European Section of the Cervical Spine Research Society. 1997;6(3):168-72.

42. Wigh RE. The thoracolumbar and lumbosacral transitional junctions. Spine. 1980;5(3):215-22.

43. Farshad-Amacker NA, Lurie B, Herzog RJ, Farshad $\mathrm{M}$. Interreader and intermodality reliability of standard anteroposterior radiograph and magnetic resonance imaging in detection and classification of lumbosacral transitional vertebra. The spine journal : official journal of the North American Spine Society. 2013.

44. Cinotti G, Postacchini F, Fassari F, Urso S. Predisposing factors in degenerative spondylolisthesis.

A radiographic and CT study. International orthopaedics. 1997;21(5):337-42.

45. Kim NH, Suk KS. The role of transitional vertebrae in spondylolysis and spondylolytic spondylolisthesis. Bulletin (Hospital for Joint Diseases (New York, NY)). 1997;56(3):161-6.

46. Mahato NK. Lumbosacral transitional vertebrae: variations in low back structure, biomechanics, and stress patterns. Journal of chiropractic medicine. 2012;11(2):134-5.

47. Brault JS, Smith J, Currier BL. Partial lumbosacral transitional vertebra resection for contralateral facetogenic pain. Spine. 2001;26(2):226-9.

48. Chalian M, Soldatos T, Carrino JA, Belzberg AJ, Khanna J, Chhabra A. Prediction of transitional lumbosacral anatomy on magnetic resonance imaging of the lumbar spine. World journal of radiology. 2012;4(3):97-101.

49. Connolly LP, d'Hemecourt PA, Connolly SA, Drubach LA, Micheli LJ, Treves ST. Skeletal scintigraphy of young patients with low-back pain and a lumbosacral transitional vertebra. Journal of nuclear medicine : official publication, Society of Nuclear Medicine. 2003;44(6):909-14.

50. Weber J, Ernestus RI. Transitional lumbosacral segment with unilateral transverse process anomaly (Castellvi type 2A) resulting in extraforaminal impingement of the spinal nerve: a pathoanatomical study of four specimens and report of two clinical cases. Neurosurgical review. 2010;34(2):143-50. 51. Abe E, Sato K, Shimada Y, Okada K, Yan K, 
Mizutani Y. Anterior decompression of foraminal stenosis below a lumbosacral transitional vertebra. A case report. Spine. 1997;22(7):823-6.

52. Ichihara K, Taguchi T, Hashida T, Ochi Y, Murakami $T$, Kawai $S$. The treatment of far-out foraminal stenosis below a lumbosacral transitional vertebra: a report of two cases. Journal of spinal disorders \& techniques. 2004;17(2):154-7.

53. Porter NA, Lalam RK, Tins BJ, Tyrrell PN, Singh J, Cassar-Pullicino VN. Prevalence of extraforaminal nerve root compression below lumbosacral transitional vertebrae. Skeletal radiology. 2014;43(1):55-60.

54. Tokgoz N, Ucar M, Erdogan AB, Kilic K, Ozcan $\mathrm{C}$. Are spinal or paraspinal anatomic markers helpful for vertebral numbering and diagnosing lumbosacral transitional vertebrae? Korean journal of radiology : official journal of the Korean Radiological Society. 2014;15(2):258-66.

55. O'Driscoll CM, Irwin A, Saifuddin A. Variations in morphology of the lumbosacral junction on sagittal MRI: correlation with plain radiography. Skeletal radiology. 1996;25(3):225-30.

56. Desmond PM, Buirski G. Magnetic resonance appearances of developmental disc anomalies in the lumbar spine. Australasian radiology.

1993;37(1):26-9.

57. Carrino JA, Campbell PD, Jr., Lin DC, Morrison WB, Schweitzer ME, Flanders AE, et al. Effect of spinal segment variants on numbering vertebral levels at lumbar MR imaging. Radiology.

2011;259(1):196-202.

58. Farshad M, Aichmair A, Hughes AP, Herzog RJ, Farshad-Amacker NA. A reliable measurement for identifying a lumbosacral transitional vertebra with a solid bony bridge on a single-slice midsagittal MRI or plain lateral radiograph. The bone $\&$ joint journal. 2013;95-b(11):1533-7.

59. Milicic G, Krolo I, Vrdoljak J, Marotti M, Roic $\mathrm{G}$, Hat J. Using magnetic resonance imaging to identify the lumbosacral segment in children. Collegium antropologicum. 2006;30(1):55-8.

60. Lee CH, Park CM, Kim KA, Hong SJ, Seol HY, $\mathrm{Kim} \mathrm{BH}$, et al. Identification and prediction of transitional vertebrae on imaging studies: anatomical significance of paraspinal structures. Clinical anatomy (New York, NY). 2007;20(8):905-14.
61. Hughes RJ, Saifuddin A. Numbering of lumbosacral transitional vertebrae on MRI: role of the iliolumbar ligaments. AJR American journal of roentgenology. 2006;187(1):W59-65.

62. Bressler EL. Numbering of lumbosacral transitional vertebrae on MRI. AJR American journal of roentgenology. 2007;188(2):W210; author reply W1. 63. Ugokwe KT, Chen TL, Klineberg E, Steinmetz MP. Minimally invasive surgical treatment of Bertolotti's Syndrome: case report. Neurosurgery. 2008;62(5 Suppl 2):ONSE454-5; discussion ONSE6.

64. Li Y, Lubelski D, Abdullah KG, Mroz TE, Steinmetz MP. Minimally invasive tubular resection of the anomalous transverse process in patients with Bertolotti's syndrome: presented at the 2013 Joint Spine Section Meeting: clinical article. Journal of neurosurgery Spine. 2014;20(3):283-90.

65. Almeida DB, Mattei TA, Soria MG, Prandini MN, Leal AG, Milano JB, et al. Transitional lumbosacral vertebrae and low back pain: diagnostic pitfalls and management of Bertolotti's syndrome. Arquivos de neuro-psiquiatria. 2009;67(2a):268-72.

66. Muir JM. Partial lumbosacral transitional vertebrae: 2 cases of unilateral sacralization. Journal of chiropractic medicine. 2012;11(2):77-83.

67. Muir JM. Chiropractic management of a patient with low back pain and Castellvi type II lumbosacral transitional vertebrae. Journal of chiropractic medicine. 2012;11(4):254-9.

68. Brenner AK. Use of lumbosacral region manipulation and therapeutic exercises for a patient with a lumbosacral transitional vertebra and low back pain. The Journal of orthopaedic and sports physical therapy. 2005;35(6):368-76.

69. Leone A, Guglielmi G, Cassar-Pullicino VN, Bonomo L. Lumbar intervertebral instability: a review. Radiology. 2007;245(1):62-77.

70. Little P, Lewith G, Webley F, Evans M, Beattie A, Middleton K, et al. Randomised controlled trial of Alexander technique lessons, exercise, and massage (ATEAM) for chronic and recurrent back pain.

British journal of sports medicine. 2008;42(12):965-8.

71. Patti A, Bianco A, Paoli A, Messina G, Montalto MA, Bellafiore M, et al. Effects of Pilates exercise programs in people with chronic low back pain: a sys- 
tematic review. Medicine. 2015;94(4):e383.

72. Burnham R. Radiofrequency sensory ablation as a treatment for symptomatic unilateral lumbosacral junction pseudarticulation (Bertolotti's syndrome): a case report. Pain medicine (Malden, Mass).

2010;11(6):853-5.

73. Endo K, Ito K, Ichimaru K, Komagata M, Imakiire $\mathrm{A}$. A case of severe low back pain associated with Richard disease (lumbosacral transitional vertebra). Minimally invasive neurosurgery : MIN. 2004;47(4):253-5.

74. Mitra R, Carlisle M. Bertolotti's syndrome: a case report. Pain practice : the official journal of World Institute of Pain. 2009;9(2):152-4.

75. Marks RC, Thulbourne T. Infiltration of anomalous lumbosacral articulations. Steroid and anesthetic injections in 10 back-pain patients. Acta orthopaedica Scandinavica. 1991;62(2):139-41.

76. Pekindil G, Sarikaya A, Pekindil Y, Gultekin A, Kokino S. Lumbosacral transitional vertebral articulation: evaluation by planar and SPECT bone scintigraphy. Nuclear medicine communications.

2004;25(1):29-37.

77. Jonsson B, Stromqvist B, Egund N. Anomalous lumbosacral articulations and low-back pain. Evaluation and treatment. Spine. 1989;14(8):831-4.

78. Santavirta S, Tallroth K, Ylinen P, Suoranta H. Surgical treatment of Bertolotti's syndrome. Followup of 16 patients. Archives of orthopaedic and trauma surgery. 1993;112(2):82-7.

79. Kikuchi K, Abe E, Miyakoshi N, Kobayashi T, Abe T, Hongo M, et al. Anterior decompression for far-out syndrome below a transitional vertebra: a report of two cases. The spine journal : official journal of the North American Spine Society. 2013;13(8):e21-5.

80. Miyoshi Y, Yasuhara T, Date I. Posterior decompression of far-out foraminal stenosis caused by a lumbosacral transitional vertebra--case report. Neurologia medico-chirurgica. 2011;51(2):153-6.

81. Shibayama M, Ito F, Miura Y, Nakamura S, Ikeda S, Fujiwara K. Unsuspected reason for sciatica in Bertolotti's syndrome. The Journal of bone and joint surgery British volume. 2011;93(5):705-7.

82. Byun WM, Kim JW, Lee JK. Differentiation between symptomatic and asymptomatic extraforaminal stenosis in lumbosacral transitional vertebra: role of three-dimensional magnetic resonance lumbosacral radiculography. Korean journal of radiology: official journal of the Korean Radiological Society. 2012;13(4):403-11.

\section{Disclosures}

The authors declare no relevant financial disclosures.

\section{Corresponding Author}

John A Bendo, Center for Musculoskeletal Care, 333 E. 38th Street, New York, NY 10016.

John.bendo@nyumc.org.

Published 29 July 2015.

This manuscript is generously published free of charge by ISASS, the International Society for the Advancement of Spine Surgery. Copyright @ 2015 ISASS. To see more or order reprints or permissions, see http://ijssurgery.com. 